\title{
Article
}

\section{Longitudinal Fluctuations of National Help-Seeking Reports for Domestic Violence Before, During, and After the Financial Crisis in Cyprus}

Kyriakidou, Marilena, Zalaf, Alexia, Christophorou, Stephanie, RuizGarcia, Ariel and Valanides, Constantinos

Available at http://clok.uclan.ac.uk/28311/

Kyriakidou, Marilena, Zalaf, Alexia, Christophorou, Stephanie, Ruiz-Garcia, Ariel and Valanides, Constantinos (2021) Longitudinal Fluctuations of National Help-Seeking Reports for Domestic Violence Before, During, and After the Financial Crisis in Cyprus. Journal of Interpersonal Violence, 36 (15-16). NP8333-NP8346. ISSN 0886-2605

It is advisable to refer to the publisher's version if you intend to cite from the work. http://dx.doi.org/10.1177/0886260519843278

For more information about UCLan's research in this area go to http://www.uclan.ac.uk/researchgroups/ and search for <name of research Group>.

For information about Research generally at UCLan please go to http://www.uclan.ac.uk/research/

All outputs in CLoK are protected by Intellectual Property Rights law, including Copyright law. Copyright, IPR and Moral Rights for the works on this site are retained by the individual authors and/or other copyright owners. Terms and conditions for use of this material are defined in the policies page. 
Longitudinal fluctuations of national help seeking reports for domestic violence before, during and after the financial crisis in Cyprus

\section{Authors}




\begin{abstract}
Although many studies generally agree that unemployment may impact domestic violence, little is known about these effects in small nations. The relationship between unemployment and domestic violence in large and small nations may be different. This is because small nations have more expensive public sectors and limited employment opportunities in comparison with larger nations. We examined how longitudinal rates of national help-seeking domestic violence contacts (DVCs) from the only non-governmental domestic violence support agency in Cyprus (a small nation) fluctuated in relation to national unemployment data between 1996 and 2016. This period included an economic crisis which commenced in 2011 and showed signs of recovery in 2015. We analyzed whether the fluctuations in unemployment registrations could predict changes in DVCs. Our analysis included 5,103,120 unemployment registrations and 21,774 DVCs. Findings supported our hypothesis and revealed unemployment predicted and correlated with DVCs. There were significant changes to DVCs when Cyprus plunged into economic crisis, meaning that when unemployment increased, DVCs also increased. Cyprus does not deviate from larger societies in help-seeking behavior in the form of people contacting a national helpline when exposed to economic crises. This study provides evidence of the link between economic hardship and increased help-seeking behaviours in small nations. Societies at risk of an economic crisis need to consider the potential impact on domestic violence rates and on demand for support services.
\end{abstract}

Keywords: Domestic violence, unemployment, economic crisis, Cyprus, small nations, unemployment, 


\section{Introduction}

The law in Cyprus defines domestic violence as: 'Any behavior or lack of behavior by a family member towards another family member that causes psychological, physical or sexual injury' (Law Commissioner, 2005). Domestic violence contacts (DVCs) are defined here as any communication (e.g. telephone calls, emails, face to face visits) revealing a domestic violence incident (e.g. intimate partner violence, child abuse in the family) to seek help or guidance from non-governmental organisations (NGOs).

The link between economic crises and domestic violence in small nations is unclear as it has only been investigated in large nations so far. The question of whether economic crises in small nations impact domestic violence in a similar way to larger nations still remains. This is important as small nations are vulnerable to global financial crises (Brito, 2015) and they comprise $54.4 \%$ of all member states of the United Nations (Súilleabháin, 2013). The present study analysed whether unemployment adversely impacted DVCs over a twenty year period which included an economic recession in the Republic of Cyprus, the $33^{\text {rd }}$ smallest nation in the world.

\section{Economic challenges, unemployment and domestic violence}

Some studies find no relationship between unemployment and DVCs (Dalal, 2011; Krishnan et al., 2010; Rahman, Hoque \& Makinoda, 2011). Other studies supported the hypothesis that economic hardship (e.g. missing bill payments) increased the risk of women becoming victims of domestic abuse in the United States (Golden, Perreira \& Durrance, 2013). A different study indicated that poorer families were more likely to have conflicting relationships compared with wealthier families in China (Zhang, 2012). Evidence shows that the employment status of Mexican (Terrazas-Carrillo \& McWhirter, 2015), and English (Anderberg, Rainer, 
Wadsworth \& Wilson, 2015) women predicted domestic violence as unemployed women were more frequently victimized than employed women. In the current study we followed a similar approach to these earlier studies and investigated the national DVCs in Cyprus.

\section{Economic crises and DVCs}

The economic power of an individual can be affected by unemployment in England and Germany (Anderberg et al., 2015), and salary in the United States (Aizer, 2010). These suggest that unemployment and salary have implications for the experience or perpetration of domestic violence. Card and Dahl (2011) analyzed data from the United States on whether professional football games affected DVCs. The emotional reactions triggered by the games had an adverse influence on family dynamics and increased the risk of violence (Card \& Dahl, 2011). as perpetrators may have induced feelings of loss of control

\section{Cyprus as a small nation}

Countries with less than 1.5 million inhabitants are defined as small by the World Bank and Commonwealth Secretariat. The relationship between DVCs and unemployment may be different in small nations compared to large nations for three reasons: Firstly, small nations have a relatively large and expensive public sector compared to the population (Brito, 2015). During economic crises, access to and the quality of services offered by the public sector may be adversely affected. This in turn can influence how victims of domestic violence gain access to those services (Dworkin, Javdani \& Allen, 2016). Secondly, small nations have limited opportunities for employment in the home country (Brito, 2015). During economic crises, these opportunities may be reduced to critical levels. For unemployed people who cannot afford to travel abroad for work, this may create a hopeless atmosphere influencing how violent incidents are perceived and reported. Thirdly, daily life in small nations can be more easily scrutinized 
with the community more aware of other peoples' personal lives (Foster, 2004). This may increase the fear of stigmatization which in turn can influence DVCs (Kumar, 2012). The combination of these three features may reveal a different relationship between DVCs and unemployment in small nations compared with larger nations.

\section{The situation in the Republic of Cyprus}

The year 2011 was considered as the start of serious financial difficulties in Cyprus (Orphanides, 2014; World Bank Report, 2015). In 2011 the gross domestic product decreased by $4.5 \%$ and unemployment rates reached a record high of $9.6 \%$ (Orphanides, 2014). In 2012, there was a downgrade of Cyprus's credit rating and unemployment escalated, reaching 17\% in 2013. In 2012 Cyprus became the fifth European government to request an economic bailout program and by 2015 Cyprus had slowly started recovering from this crisis (Hardouvelis \& Gkionis, 2016).

The Association for the Prevention and Handling of Violence in the Family (known as SPAVO) is the only NGO focusing on domestic violence on the island. As a result, the entire population of Cyprus can contact SPAVO to report or seek advice on domestic violence or seek shelter. SPAVO offers a free national helpline, shelter and counselling programs for victims or alleged victims, suspects and perpetrators of domestic violence. SPAVO has a database of domestic violence cases dating back to 1995 . This database is considered a national database for reports of domestic violence reaching the NGO.

\section{The present study}

The present study was designed to identify whether unemployment registration was associated with the DVCs to SPAVO in Cyprus before, during and after the economic crisis period. The first objective was to identify whether DVCs significantly changed before, during 
and after the economic crisis. The second objective was to explore whether the national unemployment records predict the national DVCs to SPAVO.

\section{Methodology}

\section{Procedure and data}

We sought ethical approval from the University of the first author (at the time of the research) and the board members of SPAVO. Two sources of secondary data were used, SPAVO's official records and unemployment records. We used SPAVO's official records on the cases they assist with via their helpline, shelter and counselling programs. In the early years SPAVO added the data monthly, we therefore recorded the monthly DVCs. Records were available from 1995 to 2016, with the exception of a few months in 1996, so data analyses were undertaken to include information from April 1996. Records from government agencies (e.g. police, social welfare office) have not been included due to difficulties with access.

Unemployment records are measured by the Statistical Service of Cyprus which is a governmental organisation. The Statistical Service in Cyprus was contacted to identify the unemployment records from April 1996 till December 2016. We have noted for each month the actual number of people who were registered as unemployed. These numbers are publicly available from the Statistical Service website (Statistical Service Cyprus, 2016).

\section{Design}

The independent variables were the number of unemployment registrations, before (1996 to 2010), during (2011 to 2015) and after (2016) the economic crisis. The dependent variable was the number of DVCs per month SPAVO received via its national helpline, electronic mail or face-to-face interaction. DVCs could have been received from the alleged victims, family members, non-family members or anonymous sources. When a caller contacted SPAVO to 
report an incident this was counted as one DVC. If a second caller reported the same incident this was counted as a second DVC. This was the procedure for adding DVCs to SPAVO's database making it difficult to measure the possibility of double-counting. We noted DVCs regardless of whether callers had called in the past (repeated) or for the first time (new), so all reports were included as independent observations. It is acknowledged that the DVCs consist of only a small number of the actual domestic violence incidents in Cyprus and this should be considered in the discussion of the present study outcomes.

\section{Sample}

In total, 249 months from April 1996 to December 2016 were analyzed. This time period produced a total of 5,103,120 enrolments on the unemployment register ( $M=20494.46$ per month; $S D=13481.03)$ and 21,774 DVCs $(M=87.45$ per month; $S D=36.33)$. There were 177 months before the economic crisis (1996 to 2010), 60 months during the economic crisis (2011 to 2015) and 12 months after the economic crisis (2016). Table 1 shows the average DVCs and unemployment records before, during and after the economic crisis. Table 2 shows the average DVCs and unemployment records for each year explored in the study.

\section{Table 1 here}

Table 2 here

\section{Analyses and data transformation}

The distribution of DVCs was not normally distributed $(p<.001)$. Logarithmic transformation was performed on the dependent variable (DVCs) to normalize its distribution. Based on the Kolmogorov-Smirnov test of normality, this transformation was successful $(p=$ .200). The Kolmogorov-Smirnov test was chosen above the Shapiro-Wilk test as it was more appropriate for our big sample size (Steinskog, 2006). 


\section{Results}

\section{Variance of DVCs before, during and after the crisis}

We conducted ANOVA to answer the first research question on how the periods before to, during and after the economic crisis impacted the DVCs. Keppel and Wickens (2004) argue the absence of a rule of thumb stating that unequal (big) samples make heterogeneity of variance seriously problematic. As long as there are no significant outliers, the data are normally distributed and the homogeneity of variance is not violated, unequal sample sizes should not be a problem (Keppel \& Wickens, 2004). Our data followed these assumptions. Levene's test shown that DVCs variance in the three time periods compared (before to, during and after the economic crisis) was equal $F(2,246)=.228, p=.797$.

ANOVA shows a significant difference between the three groups $F(2,246)=119.40, p$ $<.001$, partial $n^{2}=.5$. Bonferroni post hoc test shows there was a significant difference on the DVCs before $(M=71.85, S D=24.98)$ and during $(M=131.65, S D=28.54)$ the economic crisis $(p<$ $.001)$, during and after $(M=96.42, S D=27.39)$ the economic crisis $(p<.001)$ as well as before and after the economic crisis $(p<.005)$. The average reporting of domestic violence per month during the economic crisis was higher than the average reporting of domestic violence before and after the economic crisis. Graph 1 illustrates the fluctuations of the original (prior transformation) DVCs and unemployment registrations before the economic crisis, during the economic crisis and after the economic crisis. The graph shows DVCs and unemployment registrations on a scale 1:200 (300 DVCs and 60k unemployment registrations) in order to illustrate the correlation better. These results supported the first hypothesis that significant changes occurred on DVCs before, during and after the economic crisis.

\section{Graph 1 about here}




\section{Prediction of DVCs via unemployment registrations}

We conducted a simple linear regression to investigate the second research question on whether there is a relationship between national records of unemployment registrations and national records of DVCs. Here we tested whether the dependent variable number of DVCs, could be predicted by the independent variable the unemployment registrations. The proportion of variance explained by the model was $47 \%\left(\mathrm{R}^{2}=.470, F(1,247)=219.21, p<.001\right)$. Unemployment registrations emerged as positive predictors of the DVCs $(\beta=.69, \mathrm{t}=14.81, p<$ .001). This predictability and positive association of DVCs from unemployment registrations suggest that as unemployment increased, DVCs also increased. The results of these analyses supported the second hypothesis that DVCs were predicted by changes in the national unemployment records.

\section{Discussion}

The present study investigated whether DVCs and unemployment fluctuated before, during and after an economic crisis in Cyprus. The findings that emerged were consistent with earlier literature and suggested that during the economic crisis in Cyprus the DVCs significantly changed (e.g. Anderberg et al., 2015). We found that DVCs were contingent of the unemployment records. Overall, the analyses supported theoretical constructs of an existing relationship between economic crises and DVCs in Cyprus (Aizer, 2010; Anderberg et al., 2015; Card \& Dahl, 2011), and replicated research on how economic challenges and unemployment impact DVCs in small nations (Golden et al., 2013; Terrazas-Carrillo \& McWhirter, 2015; Zhang, 2012). The findings make an important contribution given that the literature on economic crises and DVCs so far is focused on larger nations. Our main conclusion was that individuals 
experiencing domestic violence in small nations do not seem to be different from larger nations in their help-seeking behaviors in the context of widespread financial hardship.

\section{Small nations in economic hardship}

The present study replicated earlier studies showing links between unemployment and DVCs as well as domestic violence incidents in small nations (Anderberg et al., 2015; Terrazas-Carrillo \& McWhirter, 2015). Cyprus as a small nation has a relatively large and expensive public sector with limited opportunities for employment in comparison to larger nations (Brito, 2015; Dworkin, Javdani \& Allen, 2016). As in large nations, the rise of domestic violence reports in small nations can also be an indirect sign that domestic violence incidents have increased. This complements a wave of studies supporting the notion that economic hardship (Golden et al., 2013), poverty (Zhang, 2012) and economic stress (Mason \& Smithey, 2012) contribute to abusive behaviours in a relationship or family. Particularly, DVC fluctuations occurred in line with fluctuations in unemployment registration. This is a key finding as small nations are much more vulnerable to global financial crises (Brito, 2015). Acknowledging that individuals display the same help seeking behavior under economic recessions, irrelevant of the size of their country, opens pathways to generalize the theoretical frameworks modelling how economic situations impact domestic violence in small nations (Aizer, 2010; Anderberg et al., 2015; Card \& Dahl, 2011).

\section{Possible explanations}

Possible explanations of why DVCs increased in Cyprus during periods of high unemployment can be due to the changes of individuals' economic power (due to their unemployment or salary) as suggested in studies conducted in England, Germany and the United 
States (Aizer, 2010; Anderberg et al., 2015). Such changes on individuals' economic power may have had implications on the individuals' experience or perpetration of domestic violence.

Another possible explanation is the 'loss-of-control' theory. Studies in the United States supported the theory that job loss leads to individuals losing control and resorting to domestic violence (Johnson, 2008; Schneider et al., 2016). Economic hardship (e.g. inability to pay rent) is considered a stressful situation (Johnson, 1995) which can intensify negative emotions like anger and hopelessness (Goetz et al., 2010; Skinner, 1996). Consequently, it is possible that these negative emotions, due to the loss of perceived control, may have changed the interactions between family members leading to an increase of DVCs in Cyprus.

These possible explanations have not been directly tested in the present study and are based on theoretical assumptions of increased DVCs in Cyprus based on earlier studies (Aizer, 2010; Anderberg et al., 2015; Card \& Dahl, 2011).

\section{Limitations and Future directions}

The study identified a trend between unemployment and the reporting of violence. However, there may be mediators or external variables influencing DVCs which were not captured by the present research. There may have been other factors that changed throughout the same timespan that may have resulted in the differences in the number of DVCs, for example, the population growth may have impacted the outcomes..

Our study focused on the reporting of domestic violence and not on the actual incidents of domestic violence. Several studies have relied on reporting as an indicator of domestic violence. For example, Copp et al., (2016) used the Toledo Adolescent Relationship and Terrazas-Carrillo and McWhirter, (2015) used data from the Mexican Instituto Nacional de Estadística, Geografía e Informática. Authorities, governmental agencies and NGOs also rely on reporting as an 
indicator of domestic violence. Even if DVCs are indicators of domestic violence incidents, it remains debatable whether the actual incidents of domestic violence increased in Cyprus during the economic crisis. The present study provides promising outcomes to stimulate further studies in exploring the rise and fall of domestic violence incidents in relation to the economic crisis.

The present study did not include data from the police force or social welfare services or reports from school or data collected within the university premises via students or any other agencies. It is important to acknowledge that each agency (e.g. police, schools) tend to extract different demographics on domestic violence as they focus on different populations (for example, reports to the police may be more severe). These important differences should be considered when interpreting the outcomes of the present study.

Finally, our outcomes relied on secondary data. One limitation of this was that the way DVCs were measured changed over time making it difficult to consider common variables recorded throughout the years beyond the number of contacts.

\section{Conclusions}

Large and small nations on the brink of an economic crisis can expect additional societal problems such as interpersonal violence (Anderberg et al., 2015; Terrazas-Carrillo \& McWhirter, 2015). Citizens of such nations are likely to experience not only the unfortunate difficulties of unemployment but they are also likely to experience increased problematic relationships within their family environment. This was observed in earlier literature in England, Germany (Anderberg et al., 2015), and the United States (Aizer, 2010). Efforts can be made to prevent such distressing atmospheres for individuals as well as handling the rise of demands related with guidance, counselling, offering shelter as well as investigating the violent incidents (Celeste, 2013; Ricciardi \& Paget, 2012). NGOs and other domestic violence services (like the police) 
have a central role in managing the prevention and handling of DVCs in economic crisis (Ricciardi \& Paget, 2012). However, in times of economic downturns, NGOs focussing on domestic violence and other domestic violence services are often neglected by national and international support, when in fact they are needed more than ever in a society (Celeste, 2013). It is suggested that NGOs and other domestic violence services should be supported to a greater extent in times of economic hardship (Celeste, 2013; Ricciardi \& Paget, 2012). Such support will aid in helping NGOs and other domestic violence services maintain the best quality of their services as the numbers of people contacting them are likely to increase significantly during such times (Anderberg et al., 2015; Terrazas-Carrillo \& McWhirter, 2015). Consequently, economic bailout programs from wealthier countries serve more than helping the economy of the countries in need. They could unintentionally act as a support to help a society maintain its domestic wellbeing. 


\section{References}

Aizer, A. (2010). The gender wage gap and domestic violence. American Economic Review, 100 (4), 1847-1859. doi: 10.1257/aer.100.4.1847

Anderberg, D., Rainer, H., Wadsworth, J., \& Wilson, T. (2015). Unemployment and domestic violence: Theory and evidence. The Economic Journal, 126, 1947-1979. doi:

10.1111/ecoj.12246

Bandura,A.(1989).Human agency in social cognitive theory. The American Psychologist, 44, 1175-1184. doi:10.1037/0003-066X.44.9.1175

Brito, J.A. (2015). Defining country size: A descriptive analysis of small and large states. Munich Personal RePEc Archive, 66149. Retrieved from https://mpra.ub.unimuenchen.de/66149/1/MPRA_paper_66149.pdf

Card, D., \& Dahl, G.B. (2011). Family violence and football: The effect of unexpected emotional cues on violent behaviour. The Quarterly Journal of Economics, 126, 103-143. doi:10.1093/qje/qjr001

Celeste, M. (2013). From global to grassroots: The European Union, transnational advocacy, and combating violence against women. New Work, NY: Oxford University Press.

Copp, J.E., Giordano, P.C., Manning, W.D., \& Longmore, M.A. (2016). Couple-level economic and career concerns and intimate partner violence in young adulthood. Journal of Marriage and Family, 78, 744-758. doi:10.1111/jomf.12282

Dalal, K. (2011). Does economic empowerment protect women from intimate partner violence? Journal of Injury \& Violence Research, 3, 35-44. doi: 10.5249/jivr.v3i1.76 
Dworkin, E.R., Javdani, S., \& Allen, N.E. (2016). If you build it, will they come? Explaining participation in family violence councils. Journal of Community Psychology, 44 (4), 442463. doi.org/10.1002/jcop. 21780

Foster, E.K. (2004). Research on gossip: Taxonomy, methods and future directions. Review of General Psychology, 8 (2), 78-99.

Goetz,T.,Frenzel,A.C.,Stoeger,H., \& Hall,N.C.(2010). Antecedents of every day positive emotions: an experience sampling analysis. Motivation and Emotion, 34, 49-62. doi:10.1007/s11031-009-9152-2

Golden, S.D., Perreira, K.M., \& Durrance, C.P. (2013). Troubled times, troubled relationships: how economic resources, gender beliefs, and neighbourhood disadvantage influence intimate partner violence. Journal of Interpersonal Violence, 28 (10), 2134-2155. doi: $10.1177 / 0886260512471083$

Hardouvelis, G., \& Gkionis, I. (2016). A decade long economic crisis: Cyprus versus Greece. Cyprus Economic Policy Review, 10 (2), 3-40. Retrieved from https://www.ucy.ac.cy/erc/documents/Hardouvelis_Gkonis_3-40.pdf

Hofstede,G. H. (Eds.). (2001). Culture’s Consequences: Comparing values, behaviors, institutions and organizations across nations ( $2^{\text {nd }}$ ed.). Netherlands: Sage.

Johnson, M. (1995). Patriarchal terrorism and common couple violence: Two forms of violence against women. Journal of Marriage and the Family, 57, 283-294.

Johnson, M. (2008). A typology of domestic violence: Intimate terrorism, violent resistance, and situational couple violence. Boston, MA: Northeastern University Press.

Keppel, G., \& Wickens, T.D. (2004). Design and analysis: A researcher's handbook $\left(4^{\text {th }} \mathrm{Ed}\right)$. London: Pearson. 
Krishnan, S., Rocca, C.H., Hubbard, A.E., Subbiah, K., Edmeades, J., \& Padian, N.S. (2010). Do changes in spousal employment status lead to domestic violence? Insights from a prospective study in Bangalore, India. Social Science \& Medicine, 70, 136-143. doi: 10.1016/j.socscimed.2009.09.026

Kumar, A. (2012). Domestic violence against men in India: A perspective. Journal of Human Behaviour in the Social Environment, 22(3), 290-296. doi: 10.1080/10911359.2012.655988

Law Commissioner. (2005). The Violence in the Family (Prevention and Protection of Victims) Laws 2000 and 2004. Republic of Cyprus.

Mason, B., \& Smithey, M. (2012). The effects of academic and interpersonal stress on dating violence among college students. Journal of Interpersonal Violence, 27 (5), 974-986. doi: $10.1177 / 0886260511423257$

Orphanides, A. (2014). What happened in Cyprus? The economic consequences of the last communist government in Europe. SSRN Electronic Journal. doi: 10.2139/ssrn.2432456

Öster, A. \& Agell, J. (2007). Crime and unemployment in turbulent times. Journal of the European Economic Association, 5(4), 752-75. doi: 10.1162/JEEA.2007.5.4.752

Pekrun, R. (2000). A social-cognitive, control-value theory of achievement emotions. In J. Heckhausen (Ed.), Advances in psychology. Motivational psychology of human development: Developing motivation and motivating development (pp. 143-163). New York, NY, US: Elsevier Science.

Pekrun, R. (2006). The control-value theory of achievement emotions: assumptions, corollaries, and implications for educational research and practice. Educational Psychology Review, 18, 315-341.doi:10.1007/s10648-006-9029-9 
Rahman, M., Hoque, A., \& Makinoda, S. (2011). Intimate partner violence against women: Is women empowerment a reducing factor? A study from a national Bangladeshi sample. Journal of Family Violence, 26, 411-420. doi: 10.1007/s10896-011-9375-3

Raphael, S. \& Winter-Ebmer, R. (2001). Identifying the effect of unemployment on crime. Journal of Law and Economics, 44 (1), 259-83. doi: 10.1086/320275

Ricciardi, W., \& Paget, D.Z. (2012). The role of non-governmental organisations in European public heatlh: 'Yes we can'. European Journal of Public Health, 22 (6), 753. doi:10.1093/eurpub/cks153

Schneider, D., Harknett, K., \& McLanahan, S. (2016). Intimate partner violence in the great recession. Demography, 53, 471-505. doi: 10.1007/s13524-016-0462-1

Skinner,E.A.(1996).A guide to constructs of control. Journal of Personality and Social Psycholgoy, 71, 549-570.doi:10.1037/0022-3514.71.3.549

Spector,P.E.,Sanchez,J.I.,Siu,O.L.,Salgado,J.,and Ma,J.(2004). Eastern versus western control beliefs at work: an investigation of secondary control, socio instrumental control, and work locus of control in China and the US. Applied Psychology, 53 (1), 38-60.doi:10.1111/j.14640597.2004.00160.x

Statistical Service Cyprus (2016). Statistical service, labour, unemployment. Retrieved from http://www.mof.gov.cy/mof/cystat/statistics.nsf/index_en/index_en

Steinskog, D.J. (2007). A cautionary note on the use of the Kolmogorov-Smirnov test for normality. American Meteor Society, 135, 1151-1157. doi.org/10.1175/MWR3326.1

Súilleabháin, A. (2013) Small states bring big ideas to the United Nations. IPI Global Observation. Retrieved from https://theglobalobservatory.org/2013/06/small-states-bringbig-ideas-to-the-un/ 
Terrazas-Carrillo, E.C., \& McWhirter, P.T. (2015). Employment status and intimate partner violence among Mexican women. Journal of Interpersonal Violence, 30(7), 1128-1152. doi: $10.1177 / 0886260514539848$

World Bank Report. (2015). Bank non-performing loans to total gross loans (\%). Retrieved from http://data.worldbank.org/indicator/FB.AST.NPER.ZS

Zhang, X. (2012). The effects of parental education and family income on mother-child relationships, father-child relationships, and family environments in the People's Republic of China. Family Process, 51 (4), 483-4. doi: 10.1111/j.1545-5300.2011.01380 
Table 1

Means of DVCs and standard deviations with unemployment records before, during and after the crisis

\begin{tabular}{lccccc}
\hline \multicolumn{2}{c}{ Months } & \multicolumn{2}{c}{ Unemployment } & \multicolumn{2}{c}{ DVCs } \\
& $\mathrm{n}$ & $M$ & $S D$ & $M$ & $S D$ \\
& & & & & \\
\hline Before & 177 & $12,536.19$ & $3,697.93$ & 71.85 & 24.98 \\
During & 60 & $40,351.57$ & $7,844.56$ & 131.65 & 28.54 \\
After & 12 & $38,593.33$ & $4,615.76$ & 96.42 & 27.39 \\
Total & $\mathbf{2 4 9}$ & $\mathbf{2 0 , 4 9 4 . 4 6}$ & $\mathbf{1 3 , 4 8 1 . 0 3}$ & $\mathbf{8 7 . 4 5}$ & $\mathbf{3 6 . 3 3}$ \\
\hline
\end{tabular}


Table 2

Means of DVCs and standard deviations with unemployment records for each year

\begin{tabular}{|c|c|c|c|c|c|}
\hline \multicolumn{2}{|c|}{ Timeframe } & \multicolumn{2}{|c|}{ Unemployment } & \multicolumn{2}{|c|}{ DVCs } \\
\hline Year & Months (n) & $M$ & $S D$ & $M$ & $S D$ \\
\hline 1996 & 9 & 9550.67 & 768.3 & 64.33 & 18.12 \\
\hline 1997 & 12 & 10424.16 & 381.59 & 88.5 & 21.66 \\
\hline 1998 & 12 & 10411.92 & 515.74 & 73.75 & 21.55 \\
\hline 1999 & 12 & 11374.58 & 617.15 & 71.67 & 13.85 \\
\hline 2000 & 12 & 10933.67 & 1554.86 & 60.50 & 18.59 \\
\hline 2001 & 12 & 9546.17 & 1383.87 & 73.83 & 27.683 \\
\hline 2002 & 12 & 10561.41 & 1657.80 & 75.08 & 32.56 \\
\hline 2003 & 12 & 11961.17 & 1511.28 & 47.25 & 15.45 \\
\hline 2004 & 12 & 12650.33 & 2594.03 & 55.42 & 22.18 \\
\hline 2005 & 12 & 13153.25 & 2618.06 & 59.92 & 20.12 \\
\hline 2006 & 12 & 12823.67 & 1512.72 & 52.17 & 11.71 \\
\hline 2007 & 12 & 12017.42 & 1684.79 & 86.92 & 19.48 \\
\hline 2008 & 12 & 11541.42 & 1561.18 & 94.00 & 18.93 \\
\hline 2009 & 12 & 17504.92 & 1926.17 & 85.00 & 18.69 \\
\hline 2010 & 12 & 22841.75 & 1721.98 & 87.58 & 28.33 \\
\hline 2011 & 12 & 28275.50 & 2203.83 & 109.92 & 25.27 \\
\hline 2012 & 12 & 36362.08 & 2464.13 & 144.67 & 36.75 \\
\hline 2013 & 12 & 46764.58 & 1971.53 & 142.08 & 19.59 \\
\hline
\end{tabular}




\begin{tabular}{llllll}
\hline 2014 & 12 & 47196.67 & 3940.39 & 136.08 & 21.72 \\
2015 & 12 & 43159.00 & 4323.22 & 125.50 & 25.36 \\
2016 & 12 & 38593.33 & 4615.76 & 96.42 & 27.39 \\
\hline
\end{tabular}




\section{Graph 1}

Fluctuations of DVCs and unemployment enrolments from 1996 to 2016

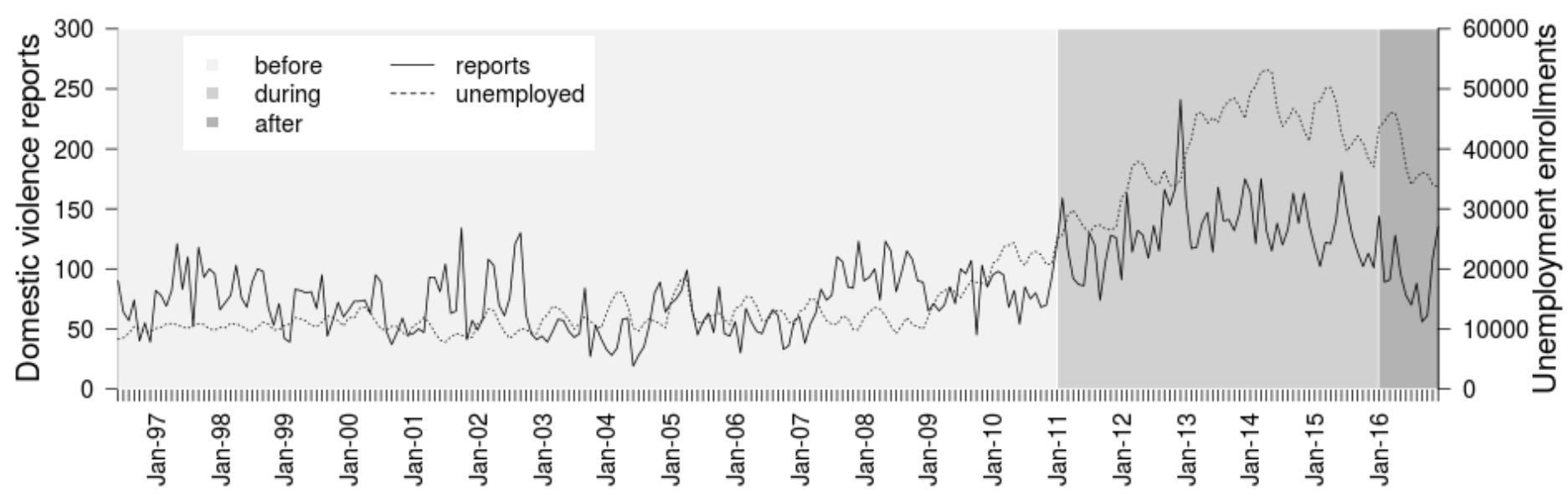

